\title{
LA ESCALA DE AMOR DE CALISTO
}

\author{
Françoise Maurizi \\ Université de Caen, Basse-Normandie
}

El amante está herido: Amor se ha apoderado de su corazón, su libertad queda cautiva. Las cuatro voluntades - entendimiento, voluntad, razón y memoria - consienten. El vencido no tiene más remedio que dar forma poética al ataque y a su propio rendición ante Amor.

A finales del siglo XV el tópico del enamorado a menudo se manifiesta en forma alegórica. Una semántica, guerrera en su esencia, da cuenta de cómo el dios omnipotente, Amor, ha llegado a adueñarse del desgraciado amante, ya herido por su flecha.

\section{El amor cortés y la poesía cancioneril.}

La ficción sentimental - y en particular las obras de Diego de San Pedro: Tratado de amores de Arnalte y Lucenda y Cárcel de amor - abre paso al tópico del cautivo de amor en la prosa del siglo $\mathrm{XV}$, en su análisis alegórico de los efectos sobre el amante del código del amor cortés. La omnipotencia del amor, en la poesía cancioneril contemporánea, preferentemente se retrata con un lenguaje más formulaico. La alegoría de la "cárcel de amor" utilizada magistralmente por San Pedro es compleja a pesar de su aparente sencillez. ${ }^{1}$ La alegoría de "la fortaleza" es más bien fácil de entender. Si la prosa prefiere aquélla, ésta se estila tanto en la prosa como en la poesía. Basta recurrir

1 Para la alegoría, vista como o "perfecta" o "imperfecta" remito a la excelente introducción de Keith Whinnom a Cárcel de amor (Madrid: Castalia, 1984). 
a los versos de Castillo de amor de Jorge Manrique para ver la facilidad con la cual es usada la alegoría de la fortaleza: ${ }^{2}$

que no puede ser tomada

a fuerça mi fortaleza

ni a trayción.

o estos otros de un romance de Juan del Encina: ${ }^{3}$

Mi libertad en sossiego, mi coraçon descuidado, sus muros y fortaleza amores me la han cercado.

La alegoría de la fortaleza se vale de una terminología guerrera: la del cerco que acarrea la imagen de una escala, la necesaria para asaltar a la amada que se encierra:

Escala d'amor

Estando triste, seguro,

mi voluntad reposaba

quando escalaron el muro

do mi libertad estaua.

A'scala vista subieron

vuestra beldad y hermosura. (Manrique, p. 26).

O consideremos estos versos:

Villancico

Si amor pone las escalas

al muro del coraçon

¡no hay ninguna defensión!

$\mathrm{Si}$ amor quiere dar combate

con su poder y firmeza

no hay fuerça ni fortaleza

${ }^{2}$ Jorge Manrique, Cancionero, edición de A. Cortina, (Clásicos castellanos, 94, Madrid: Espasa-Calpe: 1980), p. 21. Futuras citas de Manrique serán tomadas de esta edición.

${ }^{3}$ Juan del Encina, Obras Completas, III, edición de A. M. Rambaldo, (Clásicos castellanos, 220, Madrid: Espasa-Calpe, 1978), p. 154. Se seguirá citando de esta edición. 
que no tome ni desbarate. (Encina, III, 156)

Estos versos pertenecen al romance enciniano ya citado (nota 3):

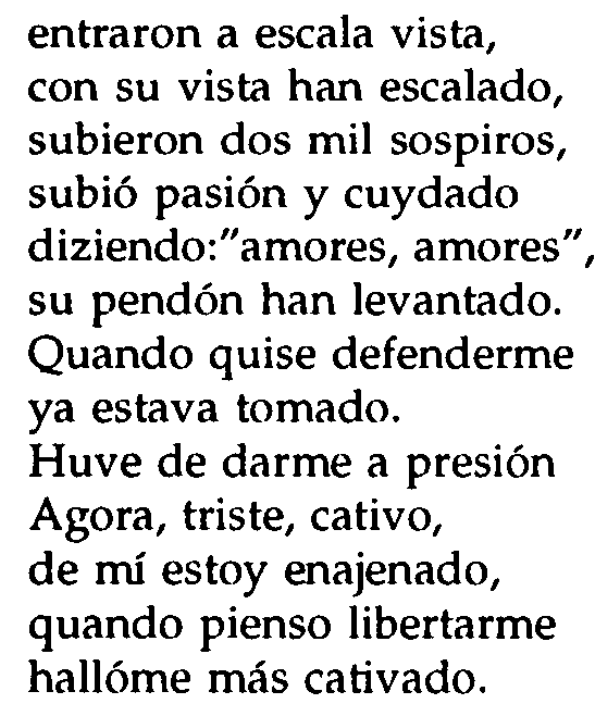

La alegoría de la fortaleza con su semántica guerrera es también reconocible en Celestina pero su funcionamiento resulta pervertido a dos niveles: (1) se ve rebajado a un nivel inferior del discurso, y (2) en la aplicación de la alegoría.

Las siguientes reflexiones sobre la alegoría de la fortaleza tienen el propósito de mostrar, primero, que Fernando de Rojas trabajó conscientemente el tópico de la fortaleza con las correspondientes metáforas $\mathrm{y}$, segundo, que lo que tenemos en la Tragicomedia no es sino una seria realización de la alegoría y las metáforas del amor cortés, y, tercero, que esta materialización de la metáfora está al servicio de una intención muy bien pensada: dar cuenta de cómo el amor idealizado por la nobleza, representado en el de Melibea y Calisto, no llega a ser más que un trato carnal. La desalegorización de la retórica cortés es absoluta. La transgresión de los preceptos del amor ideal, la que termina en la unión física de los amantes, lleva consigo la inversión (¿paródica?) de dichos preceptos. La retórica así rebajada está al servicio de una ideología. Vamos a ver cuál.

Los signos.

La fortaleza. En el Auto XVI Melibea, exasperada por lo que oye tras la puerta cuando están sus padres planeando casarla, recapitula (para el lector u oyente) como ha mantenido su relación con Calisto desde hace 
un mes: "que jamás noche ha faltado sin ser nuestro huerto escalado como fortaleza" (TCM, 538). ${ }^{4}$

Retóricamente la comparación es inferior a la imagen. Sin embargo el signo "escalar," lo mismo que el signo "fortaleza," se emplean con la intención evidente de hacer un paralelo y remitir al lector/oyente a la tan tópica alegoría. El huerto de Melibea no puede ser una fortaleza, especialmente si se toma en cuenta la polisemia de la palabra "huerto" y su fuerte connotación erótica. ${ }^{5}$ Sin embargo aquí transparenta la imagen del jardín de difícil acceso, el tópico del locus conclusus, al que volveré después. Estos tres signos, "huerto, escalar y fortaleza," abundan en la lírica amorosa, asociados como aliados.

Escalar-escala. El verbo escalar denota el movimiento de ascenso del amante hacia la amada. Las precisiones que nos va proporcionando el texto de Celestina a partir del Auto XIV - en cuanto la forma con la que se concretan los sucesivos encuentros de Melibea y Calisto, nos remiten todas ellas a la escala. Fue la utilización recurrente de la palabra - y sus contextos - lo que primero me llamó la atención. Enumeremos las frases en que hallamos la escala:

1. Calisto: "Llevarán escalas que son muy altas las paredes." (XIII, 495)

2. Pónenle el escalera. (...) y métese en la huerta donde halla a Melibea.

(...) Acabado su negocio, quiere salir Calisto, el qual por la escuridad de la noche erró la escala. Cae y muere. (XIV,497)

3. Sosia: Arrima essa scala, Tristán. (499)

4. Melibea: Baxa, baxa poco a poco por el scala. (499)

5. Calisto: Moços, poned la escala.

Sosia: Señor, vesla aquí. (504)

6. Calisto: Poned, moços, la escala y callad. (XIX, 565)

7. Calisto: Déxame, por Dios, señora, que puesta está el escala. (XIX, 574)

${ }^{4}$ Importa subrayar la diferencia entre la Tragicomedia (TCM) y la Comedia (CCM). La edición utilizada es la de Peter Russell, (Madrid: Castalia, 1991). De aquí en adelante, las citas irán señaladas en el texto.

${ }^{5}$ No desarrollaré aquí la polisemia del huerto ni el contenido erótico de ciertas otras palabras. Remito el lector al admirable artículo de J. P. Lecertua, "Le jardin de Melibée: métaphores sexuelles et connotations symboliques dans quelques épisodes de La Célestine," Trames: Etudes Ibériques 2 (Limoges) (Marzo 1978), 105-138.

${ }^{6}$ Se trata del argumento de la $C$ distinto, por supuesto, del de la $T C$. 
8. Tristán: Tente, señor, no baxes, que idos son... Tente, tente, señor, con las manos al escala. (XIX, 574)

9. Tristán: que el triste de nuestro amo es caydo del escala, y no habla ni se bulle. (XIX, 575)

10. Melibea: Quebrantó con escalas las paredes de tu huerto; quebrantó mi propósito. Perdí mi virginidad. (...) como las paredes eran altas, la noche oscura, la escala delgada $(C C M)$ (...) y él baxava pressuroso a ver un ruydo (...) con el gran ímpetu que él llevaba (TCM) non vido bien los passos (CCM). (XX, 588)

El amor y sus efectos. Melibea, al hablar del amor todopoderoso, ya muerto Calisto, expresa en prosa en el Auto XXI unos sentimientos bien parecidos a los de un poeta cancioneril:

Tú, señor, que mi habla eres testigo, ves mi poco poder, ves quán cativa tengo mi libertad, quán presos mis sentidos de tan poderoso amor...(CCM). (XX, 585, énfasis mío)

Vencida de su amor, dile entrada en tu casa. (XX, 588, énfasis mío)

Ante el amor se tiene que reconocer que "no hay ninguna defensión" (Encina, III, 156). Los temas del cautiverio, de la prisión, y del enajenamiento que asociamos con los poetas cancioneriles resultan aquí perfectamente compatibles. O sea que en el discurso de Melibea volvemos a encontrar varios de los tópicos predilectos de la poesía lírica amorosa, todo lo cual no extraña en absoluto por ser la más en boga en aquel entonces. Lo que sí merece más detenida atención es la utilización que de estos tópicos se hace.

Discurso lírico/ discurso melibeo.

Será necesario cotejar aquí dos discursos para mejor percatarse del uso que hace Fernando de Rojas de los temas de la poesía amorosa de los cancioneros y de su originalidad creativa. El poeta cancioneril preferentemente se expresa con el "yo" lírico. Es la voz que más se utiliza y es la que tenemos en los dos poetas citados arriba: Jorge Manrique y Encina. Es una lírica compuesta por hombres: el amor cortesano es un "concepto masculino," uno en la que formulan su pasión 
por la amada. Así que sale el hablante lírico, el amante penado, y no la frecuente destinataria: la mujer.

El yo hablante. Lo novedoso aquí es que no sólo Calisto expresa sus sentimientos sino también Melibea utiliza una retórica hasta ahora propia del hombre: es que el "yo" narrador es quien suele hablar metafóricamente de su pasión y de su enajamiento. En una inversión paródica de sumo interés es ahora la amada la que emplea el vocabulario amoroso y analiza las consecuencias del amor que siente. Co-protagonista de la obra, con Calisto, Melibea se declara con un discurso que cobra tanta importancia como el de su amante: ella se hace dueña de la tópica formulación varonil. Al hablar de su voluntad cautiva, de sus sentidos presos, y al utilizar el símil alegórico de la fortaleza y la escala, Melibea se sustituye al yo-hablante masculino. Rojas, ya en el Auto XIV, nos encaminaba hacia esta inversión. ¿No hace que exclame la "sin par" Melibea al ver a Calisto: "Es tu sierva, es tu cativa, es la que más tu vida que la suya estima."? ${ }^{8}$ El lector/oyente atento no podía no percibir, ya latente, la intención paródica.

La alegoría de la fortaleza: (A) el atacante. En la fortaleza, o castillo, de amor, con su semántica guerrera, el asaltante es Amor, como ya vimos. Para llevar a buen puerto su empresa guerrera, el asaltante termina por echar mano a una escala - instrumento ahora estimado imprescindible para apoderarse de lo codiciado, más allá de las hasta ahora impregnables muros o paredes.

En la (Tragi)Comedia el asaltante es Calisto. Y con él empieza la desmetaforizacón del ideal del amor cortés, cuando lo abstracto se hace real, físico. Calisto, para llegar a donde Melibea, va a utilizar una escala. 1).

${ }^{7}$ Remito de nuevo a la Introducción ya citada de Keith Whinnom (nota

${ }^{8}$ Russell, en su edición de Celestina comenta: "Las palabras de Melibea son las que acostumbraban emplear los amantes cortesanos al dirigirse a la amada." Y acerca de la exaltación de Melibea al decir: "Señor, yo soy la que gozo, yo la que gano; tú, señor, el que me hazes con tu visitación incomparable merced", Russell opina: "vuelta al vocabulario del amor cortés pero enrevesado: aquí es la amada quien agradece al amante la "merced"que acaba de concederle"(573). Lo nuevo de la situación llama la atención de Russell: "Tanto el amante como la amada se proclaman ahora siervos el uno del otro y viceversa, situación enteramente ajena al amor cortés y que pertenece más bien a los sentimientos propios del amor romántico, apasionado, que ahora empieza a dominar la relación de la pareja"(60). 
El que va escalando las paredes es ya no la imagen del "amor que pone escalas", es un loco de amor en carne y hueso, un "saltaparedes" (316), como Melibea lo había llamado sin darse cuenta de que iba a terminar este símil en una descripción real. Es uno que no piensa sino en satisfacer su deseo y, "acabado su negocio", irse, como resume - irónico - el argumento de la Comedia (497).

La alegoría de la fortaleza: (B) el asaltado. Amor quiere acaparar, tomar posesión, del corazón del amante: éste ve que no le queda más remedio que rendirse. Su parodia es evidente en Celestina no sólo en la inversión de los papeles que hemos notado arriba. Ya no es el corazón del poeta el asaltado, sino el de Melibea. Hay que reconocer un pequeño desplazamiento de la alegoría que consiste, primero, en rebajarla a un símil, "que jamás noche ha faltado sin ser nuestro huerto escalado como fortaleza" $y$, segundo, en sustituir al 'castillo' el término "huerto." Melibea es como un huerto cuyas paredes se escalan. Su propia insistencia en convidar Calisto a que acuda a citas dentro de las paredes de su huerto me parece significativa. Para el lector/oyente ingenuo Melibea explica el sentido de todo esto al dirigirse a su padre: "Quebrantó con escalas las paredes de tu huerto, quebrantó mi propósito, perdí mi virginidad" (XX, 588).

Calisto, al escalar la como fortaleza Melibea, se apodera de su virginidad: la fortaleza-huerto-cuerpo de la asaltada tiene muros que lograron quebrantar la escala del amante-saltaparedes. Así es cómo penetra el enamorado en el jardín de las delicias terrenales de la deseada amada. Gracias a la parodia de la retórica cortesana llegamos a la siguiente equivalencia:

Amor / Calisto

Huerto como fortaleza / la guardada Melibea; su virginidad Escala de amor / escala de Calisto

Locus amoenus $=$ locus conclusus.

Observamos antes que es a partir del Auto XIV cuando el loco de amor, Calisto, piensa servirse de una escala para poder estar con Melibea. A partir de la noche en la que la cita se ciñe a unas palabras intercambiadas tras las puertas cerradas del huerto de Melibea, a Calisto no le queda más remedio que asaltar esta casa. La frustración exacerbada del enamorado le transforma en un asaltante que dista mucho del fino amador descrito en el código cortés. 
Verdad es que la "sin par" Melibea es una encerrada en una casafortaleza bien protegida (Sempronio y Pármeno temen a los hombres de Pleberio). En esto Melibea es como la doncella en un vergel cerrado. El locus amoenus buscado por los amantes es un hortus conclusus: la deseada dama se encuentra sola en el centro de un jardín, un verdadero paraíso terrenal, sólo que es también rodeada de unos muros protectores. Pero es en este mismo lugar ameno, prohibido, que quiere Calisto disfrutar de Melibea, colmar su deseo, así violando los tabúes del código cortés.

Según la tradición retórica el caballero puro bien puede penetrar dentro si es respetuoso de las reglas de amor. En este caso se abren de par en par las puertas. Pero, de faltar al código, resulta expulsado. En la Tragicomedia, las palabras de clara connotación sexual intercambiadas entre los dos amantes impiden la entrada de Calisto por la vía abierta. El no comportarse como conviene al caballero de puras intenciones le obliga a escalar las altas defensas del vergel plebérico donde le espera Melibea.

La elección por parte de Rojas de jugar con las reglas del ideal vigente del amor cortés a través de su constante violación permite explicar por qué a Melibea que, aun antes de entregarse al camino de la lujuria, tan bien sabe engañar a sus padres (con la complicidad de Lucrecia), ni siquiera se le ocurre, por ejemplo, arreglárselas para sustraer las llaves del jardín (véase en particular la escena 7 del auto XII).

Rojas subraya una y otra vez esta situación - desde el auto XIII hasta el XXI - con una insistencia que es imposible pasar por alto:

1. Calisto: Llevarán escalas que son muy altas las paredes. (XIII, 495)

2. Sosia: Arrima essa scala, Tristán, que éste es el mejor lugar, aunque alto. (XIV, 499)

3. Melibea: O mi señor, no saltes de tan alto. (XIV, 499)

4. Melibea: como las paredes eran altas (...). (XXI, 588)

La caída de Calisto de paredes tan altas no puede terminar sino con su muerte: a tal final nos encamina el autor. La consecuencia de la violación del locus amoenus/hortus conilusus por el amante anti-cortés también lleva consigo su castigo.

La escala y el jardín de las delicias: simbolismo e inversión.

Las paredes son altas, y al hacer hincapié sobre el particular el autor, también rubrica negativamente las incursiones nocturnas de Calisto. Al escalar intrépido las paredes de la casa de Pleberio por primera vez Calisto, Melibea se queda asustada: "O mi señor, no saltes 
de tan alto, que me moriré en verlo; baxa, baxa poco a poco por el scala; no vengas con tanta presura" (XIV, 499-500).

El contenido cómico de la situación se desprende de la doble inversión contenida en esta exclamación de Melibea. Es ella quien cree morirse al ver a su amante escalar paredes tan altas y ponerse en tanto peligro. Al destacar la impaciencia del lujurioso Calisto, que logra así trastornar los preceptos del amor cortés, se advierte efectivamente lo peligroso del lance. $Y$ por otra parte, notado ya en la primitiva Comedia, 'acabado su negocio,' era al salir 'con presura' y no al entrar cuando encontró la muerte:

1. Tristán: Tente, señor, no baxes, que idos son (...) Tente, tente, señor, con las manos al escala. (XIX, 574)

2. Melibea: (...) él baxava presuroso (...). (XXI, 585)

Todo como si fuera necesario que el pecado se consumara hasta el extremo final, y que, en la Tragicomedia, viniera Melibea a ser sólo y nada más que un puro objeto de deseo sexual que, desde luego, la rebaja de dama inalcanzable a mujer asequible. Así, la transgresión del código cortés era total.

La escala (física) de amor de Calisto le permite apoderarse de Melibea y de consumar su pasión. Dista mucho del valor simbólico de la escala, aniquilado por el modo de su desvirtualización. El movimiento hacia arriba, explícito en el acto de subir una escala, constituye en realidad un arquetipo. ${ }^{9}$ Es ante todo la idea fundamental de un rito de pasaje muy necesario, un tránsito entre la tierra y el cielo. El simbolismo de la ascensión en el mundo antiguo cristiano se cristaliza en la visión extraordinaria, la de gozar de modo místico y anticipado del paraíso. Si echamos una mirada a las numerosas representaciones iconográficas de esta visión anticipada del paraíso, nos percatamos de que frecuentemente se realiza en un vergel cerrado (en varias iluminaciones y grabados). El término, de origen perso: pairi-daeza, significa "jardín cercado con muros." Para llegar al paraíso es necesaria una escala. Basta citar $L a$ escala del paraiso de San Juan Clímaco o el Hortus deliciarum de Herrad de

${ }^{9}$ Véase cualquier diccionario de los símbolos. Manejo el de J. Chevalier y A. Gheerbrant (Paris: Seghers). También es de sumo interés el estudio del imaginario medieval con sus lugares maravillosos. Se puede consultar con provecho el libro de M. Meslin, Le merveilleux. L'imaginaire et les croyances en Occident (Paris: Bordas, 1984), que reúne una serie de estudios y una abundante representación iconográfica rica en sugerencias. 
Landsberg, que presenta una escala de las virtudes, para comprender la importancia simbólica del tema. Tampoco queremos olvidar su representación en el Cantar de los Cantares, la cual es asociada a la imagen de la mujer ubicada en el centro de un hortus conclusus.

La ascensión de Calisto vuelve a utilizar el simbolismo del escala del paraíso. Es la misma escala alta y delgada (ya notamos la insistencia en la idea), la misma llegada al paraíso-vergel amoroso - subrayado cuando Calisto, en el Auto XIV, intentar revivir, vuelto a casa, su encuentro con Melibea: "de día estaré en mi cámara, de noche en aquel paraíso dulce, en aquel alegre vergel, entre aquellas suaves plantas y fresca verdura" (513); y explicitado de modo asombroso por el autor en su larga amplificatio. En efecto es imposible olvidar, al principio del Auto XIX, la escena en la cual Melibea se recrea en este vergel. Contiene todos los elementos decorativos: la "fuente clara," la presencia de los "dulces árboles sombrosos," que son "altos cipreses," los "ruiseñores" para poder cotejarse con el hortus deliciarum de la tradición judeo-cristiana. $Y$ en varios aspectos no dista mucho del Cantar de los Cantares.

Sin embargo estas semejanzas con el paraíso van desapareciendo, entrado el amante en el huerto. Mientras permanecía escondido en lo alto del muro, mirando y escuchando el cantar de Melibea y Lucrecia, el parecido sigue válido. Pero en el ascenso simbólico del hombre hacia el paraíso no hay bajada, ni (a)salto necesario para llevarlo a cabo. La entrada en el paraíso no se logra con fuerza. En el caso de Calisto, su llegada no significa ninguna purificación sino, más bien, el consumo/consumación del deseo ("el que quiere comer el ave quita primero las plumas"). El simbolismo de la escala encuentra aquí su máxima inversión. ${ }^{10}$

El pecado repetido de su lujuria lo facilita la escala, y será por la escala, instrumento del pecado, que muere; el paso en falso que el pecador comete, lo dará Calisto al salir de su jardín de las delicias, del huerto-sexo de Melibea, que lo había conquistado cual fortaleza.

\section{"Libro divi-, si encubriera más lo huma-."}

Quien ama (religiosa o cortésmente) se vale, pues, de una 'escala' que le lleva a un paraíso-vergel del gozo. Pero aquí, Calisto, anti-cortés, busca sólo gozar del cuerpo de Melibea. Se trata de un subida y bajada

${ }^{10}$ Véase "la escala del paraíso" de Juan Clímaco. En vez de liberarse de sus pasiones, Calisto se entrega a ellas. La caída es inevitable. 
y no de una subida continua. El trato carnal, perfectamente puesta en evidencia en la obra, desemboca en su castigo inmediato en la Comedia (enseñando así su ejemplaridad), mientras ese castigo se aplaza en la Tragicomedia al alargar "el processo de su deleyte destos amantes" (202). Aun así, la nueva adición logra explicitar más el valor de la escala. Es asimismo imprescindible recordar lo añadido por el autor en el discurso final de Melibea: "Quebrantó con escalas las paredes de tu huerto, quebrantó mi propósito. Perdí mi virginidad. Del qual deleytoso yerro de amor gozamos quasi un mes" (XX, 588, énfasis mío). Fuera de la confirmación de la duración de estas relaciones, tenemos la afirmación de Melibea de que el placer es de pecado repetido ('yerro de amor'), pecado de luxuria y voluptas que transgreden la moral más alta.

La parodia del amor cortés consiste claramente en Celestina no sólo en la desmetaforización del código, o sea, en la inversión del simbolismo de la escala del paraíso: pierde su valor sagrado, sino también en la afirmación rotunda del placer carnal. Verdad es que el deseo sexual es el origen del amor humano. ${ }^{11}$ Pero $i " n o$ es el diablo el creador del amor lujurioso?"12

Marcel Bataillon ha escrito: "Pineda inclinait à croire les romans de chevalerie moins nocifs précisemment parce qu'ils laissent dans l'ombre 'la pratique charnelle' tandis que la Célestine 'représente' (ou évoque) les actes mêmes de l'amour physique."13 Por cierto. Sin embargo la pareja Calisto-Melibea sabe usar de una terminología que es la del amor cortés y Rojas hace que ambos materialicen los valores simbólicos-metafóricos del código cortés. El elemento paródico consiste en rebajar los ideales: el amor cortés, el fino amador, la "sin par," el trato honesto. $\mathrm{Y}$ todo por valerse de y anegarse en el deseo carnal. El código

11 Andreas Capellanus: Tractatus de amore. Véase en particular el Libro I, Capítulo I: "¿Qué es el amor?". Calisto es el arquetipo del obsesionado tal como lo describe Andreas.

${ }^{12}$ Capellanus, Libro III, "De la condenación del amor." La desobedencia a los buenos preceptos lleva a la pareja que se entregue a los de la lujuria, que de preferir el paraíso al encuentro con la muerte, así en conformidad con el castigo divino. ¿Debemos entender la obra, por medio de la caída mortal de Calisto de la escala, como un "libro de buen amor"? El recurso a la ambigüedad tan tradicional en la literatura medieval no se puede descartar en una obra de clara intención paródica a finales del siglo $\mathrm{XV}$.

165.

13 "La Célestine" selon Fernando de Rojas (Paris: M. Didier, 1961), pp. 164- 
cortés enmascaraba lo humano; Rojas, al desmetaforizarle, lo descubre.

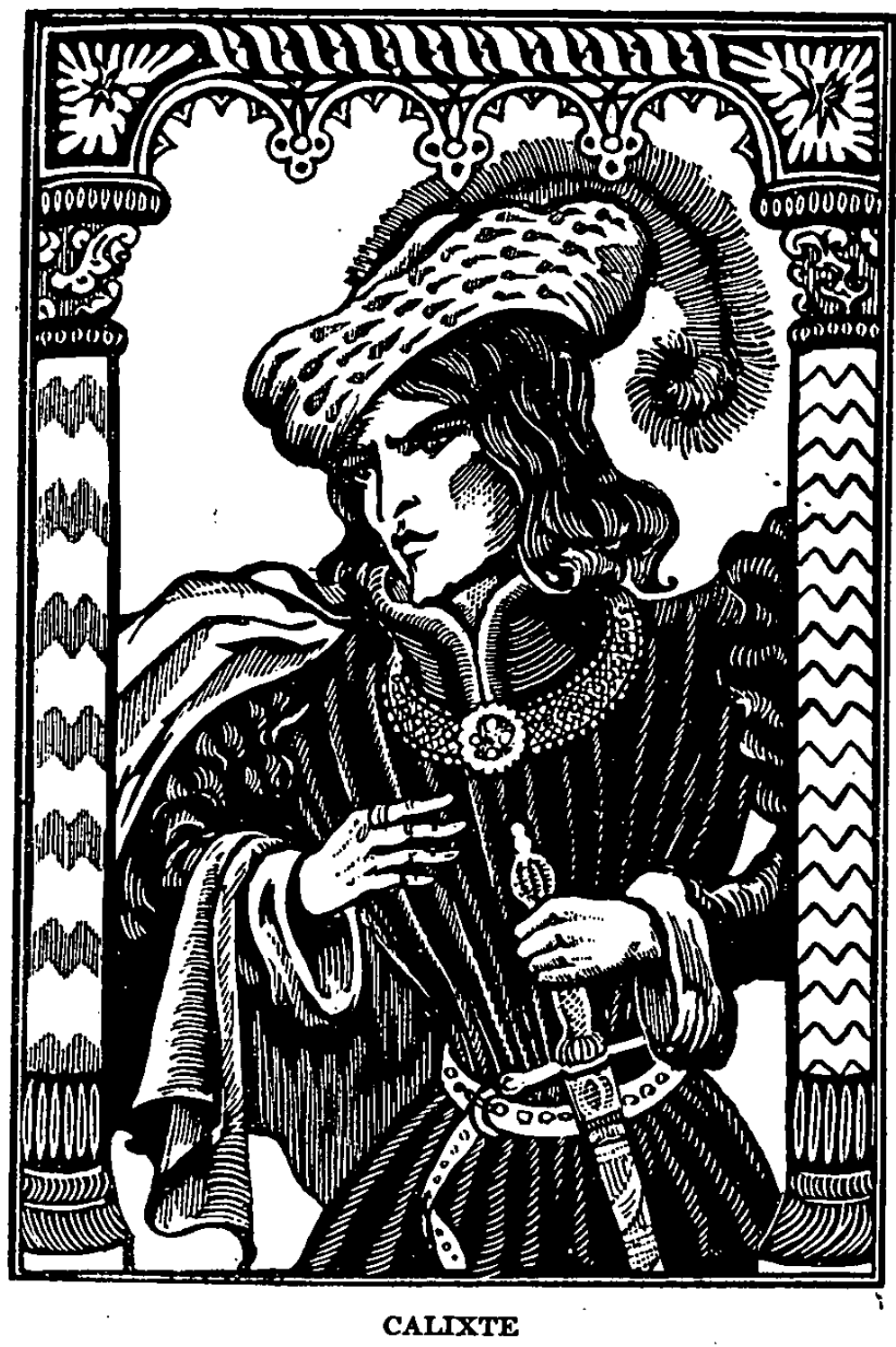

Calisto. Ilustración de Haurice Hoir (1943). 